\title{
O ESCOPO DO PODER JUDICIÁRIO DIANTE DA PROTEÇÃO AMBIENTAL NO ESTADO ECONÔMICO
}

\author{
Gina Vidal Marcílio Pompeu ${ }^{1}$ \\ Jorge Di Ciero Miranda ${ }^{2}$
}

\begin{abstract}
Resumo
Por meio do presente artigo pretende-se analisar a atuação do Poder Judiciário diante da demanda de proteção ambiental, prevista no artigo 170, Título VII da Constituição brasileira de 1988, que trata da "Ordem Econômica e Financeira". Demonstra-se que a dicotomia entre crescimento econômico e desenvolvimento humano exige do Poder Judiciário brasileiro postura capaz de converter o processo judicial em instrumento e oportunidade adequados à interferência legítima em política ambiental. A incursão na formação do Estado econômico permite identificar, entre as posturas liberal, reguladora ou intervencionista, a que melhor identifica o Brasil em 2015. Nessa vertente, a defesa do meio ambiente é vista como dever geral, direito fundamental e valor, todos capazes de balizar atuação do Poder Público e os agentes sociais. Juntamente com o crescimento econômico, a defesa do meio ambiente se agrega às preocupações sociais para construir o conceito de sustentabilidade. Após definir sustentabilidade, o texto avança no sentido de indicar os limites da atuação do julgador, investiga as hipóteses de ativismo. Sob o ponto de vista da natureza, a pesquisa é aplicada. Quanto à abordagem é qualitativa, já em consideração aos objetivos é exploratória. Com relação aos procedimentos técnicos é bibliográfica, documental e jurisprudencial.
\end{abstract}

Palavras-chave: Poder Judiciário. Proteção Ambiental. Ordem Econômica. Desenvolvimento humano. Ativismo.

\section{INTRODUÇÃO}

A preocupação central expressa nesse artigo consiste em revelar a possibilidade da participação do Judiciário no redirecionamento de política de desenvolvimento no Brasil, de modo a torná-la compatível com a defesa do meio ambiente conforme as diretrizes traçadas pela Constituição de 1988. Para isso, serve-se de Tratados e Convenções internacionais, decisões judiciais adotadas no Brasil e na Holanda, capazes de auxiliar na compreensão do princípio da defesa do meio ambiente. O viés econômico decorre da inclusão da defesa do meio ambiente como princípio da ordem econômica, previsto no artigo 170 da Constituição brasileira.

A escolha pela decisão da Suprema Corte holandesa, ocorrida em junho de 2015 deveu-se ao caráter

\footnotetext{
${ }^{1}$ Doutora em Direito pela Universidade Federal de Pernambuco (UFPE); Coordenadora e Professora do Programa de PósGraduação de Mestrado e Doutorado em Direito Constitucional da Universidade de Fortaleza (UNIFOR). E-mail: ginapompeu@unifor.br

${ }^{2}$ Juiz de direito da Vara de Trânsito no Estado do Ceará. Mestrando pela Universidade de Fortaleza (UNIFOR). Especialista Processo Penal (ESMEC/UFC) e Processo Civil (ESMEC/UVA).E-mail: jorgediciero@hotmail.com
} _vol.09, n. 01, Rio de Janeiro, 2016. pp. 324-348 
ousado do qual se reveste, além de funcionar como paradigma para decisões em outros países que enfrentam problemas ambientais. A decisão apresentada determina que o Estado holandês promova significativa diminuição na emissão de poluentes geradores de alterações climáticas. Apesar do reconhecimento de que a concretização das diretrizes estabelecidas pela sentença acarretaria expressivo e imediato ônus econômico para o país, a Suprema Corte optou por estipular novo ritmo de implementação das metas de redução de gases de efeito estufa, priorizando a preservação da qualidade do ar e dos interesses das gerações futuras. Ela é bastante emblemática também porque reconhece que não é possível estabelecer transição de modelo energético ou de consumo sem esforço e sem o engajamento de toda a sociedade.

O provimento judicial holandês tem por fundamento o compromisso assumido internacionalmente na defesa do meio ambiente. Da perspectiva teórica, sua fundamentação se baseia no princípio da precaução e dos efeitos deletérios decorrentes das externalidades negativas potencializadoras da "sociedade do risco". A busca do Judiciário como alternativa à solução de problemas ambientais, aos moldes do que acontece na Holanda, vem sendo seguida por outros países como as Filipinas e a Bélgica.

A abordagem do tema é feita a partir de objetivos parciais específicos. Assim, começa pela demonstração da importância do meio ambiente, pelo status jurídico que a sua proteção alcançou na Constituição brasileira e nos tratados internacionais. Prossegue destacando que o meio ambiente é garantia de sobrevivência biológica da espécie humana e que ainda é o único capaz de assegurar a continuidade da vida.

Reconhecer que os recursos naturais têm importância diferenciada, por cumular destaque jurídico e biológico, não basta para identificar o papel que desempenham enquanto insumos econômicos, suscetíveis de exploração racional. Sustentabilidade deve contemplar a compatibilidade entre preservação e utilidade econômica dos recursos naturais. Nessa vertente, o direito contribui para essa compatibilidade na medida em que prescreve a qualidade, extensão e forma de apropriação privada do componente natural e assegura a preservação de manancial indispensável à garantia da qualidade de vida para a espécie humana. Do enfrentamento e conciliação dessas duas ideias é que deve ser construído o conceito de sustentabilidade.

Toma-se ainda como objetivo específico do trabalho, a definição das partes e objeto jurídico aptos a viabilizar a intervenção judiciária, em matéria de políticas públicas ambientais. Surge, para tanto, a visão de meio ambiente protegido como direito fundamental. Essa ideia não importa em descuidar da natureza jurídica múltipla que a expressão "defesa do meio ambiente" carrega, pois ela contempla também a noção de dever e princípio constitucional. $\mathrm{O}$ reconhecimento do direito fundamental à defesa do meio ambiente legitima seus titulares a servirem-se das três funções estatais, inclusive da judiciária, para garanti-lo.

Sabe-se que os comandos de adequação ambiental se dirigem a todos indistintamente e também ao Estado, seja na condição de ente econômico, ou de pessoa jurídica de direito público externo. O Estado pode ser 
demandado judicialmente por ser detentor de obrigações operacionais própria, ou como responsável pela elaboração de políticas públicas. Qualquer que seja a ótica com que se reporte à ação estatal, existe sempre um dever de agir. Ocorre que sua ação encontra limites estruturais e principiológicos: a atuação estatal não pode comprometer seu sistema econômico e precisa posicionar-se adequadamente para definir e compatibilizar proteção ambiental e a indução ao crescimento econômico.

O último objetivo específico do artigo consiste em consolidar a noção de que o comprometimento do Estado com a defesa ambiental não se processa apenas com o Executivo, exige o envolvimento das suas três formas de expressão, de sorte a vincular qualquer dos integrantes da tríade que o compõe. Por esse ponto de vista, a atuação judicial é avalizada pela delimitação do conceito de ativismo, juntamente com a descrição das hipóteses em que acontece e se justifica. Para alcançar esse objetivo, são enumerados exemplos jurisprudenciais que ilustram como se dá a participação judicial em políticas ambientais, sinalizando possibilidades para a realidade brasileira.

Como delimitação histórica, parte-se de 1972, em Estocolmo, quando aconteceu a conferência convocada pela ONU para tratar de princípios básicos para a proteção ambiental: a Conferência sobre o Meio Ambiente Humano. Depois dela, seguiram-se outros eventos de magnitude, como a Conferência do Rio (ECO 92), que resultou na "Declaração do Rio" sobre meio ambiente. Em setembro de 2000, 189 nações firmaram compromisso para combater a extrema pobreza e outros males da sociedade, por meio da realização de oito "Objetivos de Desenvolvimento do Milênio (ODM) ", que deveriam ser alcançados até o fim de 2015. Esse movimento ficou conhecido como "Declaração do Milênio" e integra o Programa das Nações Unidas para o Desenvolvimento. Garantir a sustentabilidade ambiental é o sétimo desses objetivos.

A importância de identificar a relação entre crescimento econômico e desenvolvimento humano deve-se à contribuição conjunta do jurídico, do político e do econômico. O tema é enriquecido com instrumentos de cada uma dessas áreas do conhecimento quando contrapõe a dificuldade em conciliar a cultura individualista e a ineficiência do Estado com a pretensão de atender as demandas sociais.

O entendimento preponderante no Judiciário brasileiro traz a lume a consolidação do processo judicial como ferramenta útil para dotar os princípios constitucionais de força efetiva para a regulação das relações sociais. A utilização do Judiciário como locus adequado para dirimir conflitos inerentes à efetivação de políticas públicas ambientais evita que a matéria fique adstrita às deliberações de gabinete dos outros dois Poderes. O princípio da inafastabilidade previsto no artigo 5, XXXV da Constituição brasileira de 1988 garante que a lei não excluirá da apreciação do Poder Judiciário lesão ou ameaça a direito o que legitima o Judiciário para constituir-se foro para onde podem convergir expectativas coletivas legítimas. A existência de um rito preestabelecido assegura oportunidades simétricas aos interessados e a anterioridade da lei proporciona redução dos conteúdos discricionários. Essas duas características - simetria e previsão legal anterior - asseguram criticidade à decisão e, 
com isso, condições para estipular bases de consenso e pontos divergentes, em torno dos quais o jurídico pode contribuir.

Cumpre ressaltar, a preocupação em demonstrar a impropriedade do maniqueísmo que insiste em colocar em lados antagônicos o crescimento econômico e a preservação ambiental, quando na verdade são realidades que se completam e ambas custeiam a parte do desenvolvimento humano que atende pelo nome de sustentabilidade.

Essa mesma visão parcial, que enxerga crescimento econômico e a preservação ambiental em posições opostas, só consegue conceber a participação do Judiciário como intromissão na atribuição dos outros dois Poderes, particularmente quando se manifesta sobre a implementação de políticas públicas, ou da concretização de direitos que demandam ação positiva. A decisão da Corte holandesa parece convergir para a ideia de que as políticas públicas, sejam elas decorrentes da subscrição de tratados, ou concebidas internamente não são compromisso apenas do Executivo, nem tampouco exclusivas dos três Poderes, mas de toda a sociedade.

Sob o aspecto metodológico tem-se a hipótese geral de que é adequada a intervenção judicial para orientar políticas públicas que digam respeito à defesa do meio ambiente. Busca-se a confirmação da hipótese através da abordagem peculiar aos estudos jurídicos que se utiliza da redação normativa como fonte primária, até encontrar no estudo de caso, elementos que subsidiam a hermenêutica constitucional.

Para alcançar horizontes mais amplos, serve-se de conceitos próprios da economia e teoria política. Segundo o alcance do desenho, a pesquisa é exploratória conforme se vê pela ausência de consenso sobre a natureza da intervenção judicial para casos em que não há previsão legislativa específica. É também descritiva por manejar conceitos que definem o direito fundamental, capitalismo e mercado. Segundo a dimensão temporal da coleta de dados é prospectiva porque pretende regular e dispor para o futuro, baseando-se em dados coletados no presente, no atual estado de compreensão e prática da defesa do meio ambiente, fazendo da pesquisa sincrônica. A atualidade da pesquisa é alcançada por meio da busca de informações em sítios especializados, em revistas jurídicas e pesquisa jurisprudencial, o que permite classificar a coleta de dados em bibliográfica e documental.

Reafirma-se que, a contribuição jurídica, almejada nesse artigo, é oferecer interpretação que contemple o Judiciário como integrante da atuação estatal e não como agente externo que delibera sobre atribuições que não lhe são próprias. A pesquisa verifica que não há mercado, produtos ou liberdade de iniciativa quando se está diante da natureza estéril, esgotada em recursos e exaurida pela utilização irracional.

Salienta-se por fim, que os ganhos em escala, proporcionados por intermédio da revolução industrial, pouco significam se for desprezada a necessidade de que as atividades econômicas estejam inseridas em ciclo capaz de assegurar perenidade dos fundamentos econômicos, do desenvolvimento humano e da sustentabilidade. 


\section{DIREITO FUNDAMENTAL A DEFESA MEIO AMBIENTE E SUSTENTABILIDADE}

As religiões que descendem do Judaísmo identificam a predestinação do homem de preponderar sobre a natureza. Ela é vista como bem disponível para fruição ${ }^{3}$, nos dizeres de Waldir Mantovani (2009, p. 3) “[a] idéia judaico-cristã de que o homem é feito à imagem de Deus, ao invés de representar o homem apenas como um animal superior, essa concepção o elevava a um estado completamente diferente, a meio caminho entre animais e anjos". No entanto, a pretensão de completude da ciência humana vem aos poucos despertando para o reconhecimento das feridas narcísicas, conforme relatam Carlos Alberto Carvalho e Marco Túlio Sousa (2013, p.111).

Lembra-se que a crença de superioridade do homem encontrou resistência inicial diante das teorias de Galileu e Nicolau Copérnico. No século XVI os dois conseguiram apresentar modelo matemático rudimentar que demonstrava ser o Sol, e não a Terra, o centro do sistema que inclúáa o planeta habitado pelos seres humanos. Com essa demonstração solaparam a pretensão humana da Terra ser o "centro do universo".

Charles Darwin, no século XIX, frustra a ilusão de que o corpo biológico do ser humano teria descendência e semelhança divina quando apresenta a teoria evolucionista e remete sua origem aos símios: 0 condicionamento humanoide aprisionava o ser humano numa realidade animal. $\mathrm{O}$ terceiro golpe à racionalidade vem com Freud (1996), ele retira da consciência a primazia pelo governo das ações e comportamentos humanos ao desenvolver a ideia de inconsciente. A quarta ferida é representada pelo desafio ao método científico, haja vista que nem sempre, ele é capaz de produzir a verdade.

Argumenta-se que em matéria ambiental a crise do método enseja ruptura epistemológica: é o homem que depende da Terra, e não o inverso. Conforme se pode inferir do auxílio de Anatércia Rovani (2011, p.42), o ser humano se sujeita aos comandos geológicos, e eles são contados em eras. Não é o planeta que se subordina à engenharia humana, a ela cabe a evidência de que as transformações e manuseio da natureza foram o meio pelo qual a espécie humana encontrou para sobreviver e multiplicar-se:

Apresenta-se a visão predominante na modernidade na qual o homem se encontrava a parte da natureza, ou seja, como um mero utilizador ou explorador daquela. A partir disso, demonstra-se a noção pós-moderna e menos antropocêntrica da forma de perceber a natureza, na qual o ser humano passa a ser compreendido como parte integrante do meio ambiente, numa relação de dependência. (ROVANI, 2011.p. 42)

Nesse mesmo sentido, pode-se dizer, aproveitando a expressão de Waldir Mantovani (2009. p. 7), que “o homem pertence à natureza, mas ao mesmo tempo, a transcende. Encontra-se submerso no mundo físico, mas é um ser pessoal que possui dimensões não materiais". Daí decorrem três princípios correspondentes à conservação

\footnotetext{
${ }^{3}$ Então Deus disse: 'Façamos o homem à nossa imagem e semelhança. Que ele reine sobre os peixes do mar, sobre as aves dos céus, sobre os animais domésticos e sobre toda a terra, e sobre todos os répteis que se arrastem sobre a terra.' 27. Deus criou o homem à sua imagem; criou-o à imagem de Deus, criou o homem e a mulher." Disponível em < http://www.bibliacatolica.com.br/01/1/1.php> Acesso em: 06 jul. 2015
} 
biológica pensados por Meffe \& Carrol (1994, p. 13):

1. A evolução é o axioma básico que une toda a biologia (o jogo evolutivo);

2. O mundo ecológico é dinâmico e em estado de não equilíbrio (o teatro ecológico); e

3. A presença humana precisa ser incluída nos planos de conservação (os seres humanos são parte do jogo). Há uma crise de inserção biológica do homem:

Vivemos em uma sociedade que ainda hoje não percebe o mundo a sua volta de forma que não se vem fazendo parte do meio natural que os cerca, as pessoas não se vêm, pertencendo à natureza e sim a natureza pertencendo a elas, como se toda esta biodiversidade estivesse sido criado especialmente para servi-los. (COLOMBO, DIAS, MONTEIRO COELHO, 2012, p. 63)

Contudo, a limitação existencial do ser humano não é suficiente para inibi-lo na busca de soluções coletivas para problemas individuais. Reitera-se que o antigo duelo entre os direitos de desenvolvimento individual, situados na seara da liberdade, e os direitos à efetivação do bem-estar coletivo inseridos na esfera da igualdade permanece ativo por meio da exigibilidade judicial dos direitos sociais. (POMPEU, 2012, p.118)

As calamidades naturais que ameaçam a ocupação dos espaços terrestres pelo homem ocorrem no âmbito global. No Brasil, elas acontecem prioritariamente como resultado da indigência da ocupação dos espaços urbanos, da negligência no planejamento e reproduzem as duas formas pelas quais John Rawls (2008) entende o processo de exclusão e caos social: de um lado, a cultura individualista, de outro a inefetividade do Estado em atender às demandas sociais. Pode-se dizer ainda, que as intervenções prejudiciais não decorrem apenas de omissões ou planejamentos inadequados, mas também da ação humana, deliberada e transformadora, que compromete irreversivelmente o equilíbrio natural.

Ao tempo em que se registra a busca pela convergência do crescimento econômico com o desenvolvimento humano, identifica-se na sustentabilidade a expressão mais próxima da preservação ambiental. Dessa forma, o Poder Judiciário se revela aliado na promoção de políticas públicas efetivas em matéria ambiental. Conforme expõem Renata Cidin e Ricardo Silva, a sustentabilidade está diretamente relacionada à continuidade da relação do homem com a natureza, à preservação da capacidade de reprodução dos ecossistemas, ou seja, a capacidade da natureza em regenerar e absorver os resíduos:

Para que se possa caminhar em direção à sustentabilidade, é preciso que se saiba onde estamos e para onde estamos indo, do reconhecimento do que é biofisicamente possível em uma perspectiva a longo prazo e de melhores esclarecimentos e dimensionamentos dos limites de dependência dos componentes naturais e dos limites de inserção humana na natureza. Os ecossistemas se diferem na sua capacidade de suportar alterações impostas pelas atividades antrópicas: assimilar os resíduos gerados e continuar a fornecer os recursos necessários. A estabilidade ecológica é a grande "chave" da sustentabilidade. (CIDIN, SILVA, s.d, p.5).

Se por um lado existe regulamentação sobre a apropriação privada de recursos naturais, por outro, o ordenamento deve impedir a partilha indiscriminada do ônus da degradação como corolário do princípio do poluidor-pagador. Para Edis Milaré (1998, p. 182) esse princípio se assenta na “vocação redistributiva do Direito vol.09, nº. 01, Rio de Janeiro, 2016.pp. 324-348 
Ambiental e se inspira na teoria econômica de que os custos sociais externos que acompanham o processo produtivo (v.g., o custo resultante dos danos ambientais) devem ser internalizados".

Para alcançar o desiderato pretendido, a imposição de limites à prática econômica predatória é legitimada, fundamenta-se, não apenas no dever constitucional de preservar o meio ambiente, mas também na distribuição proporcional do proveito e do ônus gerado. A bilateralidade, própria da norma jurídica (VASCONCELOS, 2014, p. 715), importa no compromisso em considerar a repercussão coletiva das concessões que se faz ao empreendedor privado. Esse processo de privatização, como bem lembrou Avelãs Nunes (1997, p. 38) "trouxe consigo a necessidade de garantir a salvaguarda de determinados interesses públicos", o ambiental entre eles.

Essa explicação demonstra que a degradação ambiental afeta o espaço comum, o habitat. Pode-se dizer que mesmo a parcela da coletividade não beneficiada com o processo econômico que a gerou, vê-se diminuída da fruição de direitos indivisíveis. De acordo com o disposto no artigo 225 da Constituição de 1988, que qualifica o meio ambiente como "bem de uso comum do povo e essencial à sadia qualidade de vida", a omissão em inibir atividades que ameacem esse patrimônio jurídico importa em compelir todos os seus titulares a sofrer tais consequências.

Os desmoronamentos, enchentes, chuva ácida ou qualquer outra forma de ameaça à ocupação humana nem sempre acontecem de modo a tornar possível identificar a causa desses fenômenos, ou mesmo sua origem no tempo (CIDIN; SILVA, s.d., p. 3). Nesses processos de degradação não há um único responsável, não há como apontar ação específica exclusiva a qual reconheça origem exclusiva das repercussões ambientais. Com a exclusão de situações emblemáticas de vazamento de óleo e acidentes nucleares, pode-se dizer que o comprometimento da sadia qualidade de vida resulta de ação coletiva que chega a atravessar gerações. A percepção de que a capacidade de imprimir efeitos nefastos foi ampliada com a tecnologia e desenvolvimento de artefatos de guerra foi captado por Ulrich Bech (1998):

O final do outro, o fim de todas as nossas chances de distanciamento, chegou tão sofisticado; um final que se tornou palpável com a contaminação nuclear. Você pode deixar fora a miséria, mas não os perigos da era atômica. É aí que reside as novas forças culturais e políticos da época. Seu poder é o poder do perigo que suprime todas as áreas protegidas e todas as diferenciações da modernidade. ${ }^{4}$

Ainda que fosse possível estabelecer a correlação entre a ação danosa e o resultado, o modelo intersubjetivo do processo judicial, centrado no litígio e com ônus probante distribuído à vítima, o torna ferramenta de difícil manuseio. Dotá-lo de utilidade para questões ambientais obriga reformulação, sob pena de se

\footnotetext{
${ }^{4}$ No original: Ha llegado el final de los otros, el final de todas nuestras posibilidades de distanciamiento, tan sofisticadas; un final que se ha vuelto palpable con la contaminación atómica. Se puede dejar fuera la miseria, pero no los peligros de la era atómica. Ahí reside la novedosa fuerza cultural y política de esta era. Su poder es el poder del peligro que suprime todas las zonas protegidas y todas las diferenciaciones de la modernidad.
} 
desperdiçar a oportunidade para que ele seja espaço adequado de pacificação social. De tal constatação pode-se dizer que a limitação do modelo inter partes enseja alternativas dentro do próprio sistema, como a ressignificação dos seus instrumentos.

Uma dessas operações seria exatamente a tendência que se vê de inclusão necessária do Estado no polo passivo, chamando-o a participar da solução do problema, mesmo quando não figure como responsável direto pelo evento danoso, conforme se percebe no acórdão que segue:

O quadro evidencia uma subversão dos princípios: o interesse privado predomina sobre $\mathrm{o}$ público; ao invés da presunção de veracidade e legalidade do ato administrativo, a presunção absoluta de razão da parte que litiga com o Estado. Nas ações de indenização, em matéria de responsabilidade civil do Estado, faz-se a aplicação generalizada e nem sempre cabível da chamada teoria objetiva, com a condenação da parte pública mesmo quando inexistente o nexo de causalidade entre suas ações ou omissões e os danos (Voto-vista na Ação Rescisória no 2001.01.00.037276-0, Terceira Seção. Autor: Destilaria Alcidia S/A. Demandado: União Federal. Relator: Desembargador Federal Souza Prudente.)

Pondera-se que a salvaguarda desses interesses coletivos, em matéria ambiental, é albergada sob os princípios da prevenção e precaução. O risco concreto ou potencial é controlado pelo princípio da prevenção, enquanto o abstrato encontra-se amparado no princípio da precaução. Conforme restou definido no "Princípio 15" da Declaração sobre o meio ambiente do Rio de Janeiro ${ }^{5}$ em 1992, o princípio da precaução consiste em medidas economicamente viáveis para prevenir a degradação ambiental, quando houver ameaça de danos graves ou irreversíveis, mesmo na ausência de certeza científica absoluta, nesse sentido assevera Ana Gouveia Martins que:

O princípio da precaução se distingue da prevenção porque esta última pressupõe relação causa-efeito unívoca, exigindo uma intervenção antes da ocorrência do dano certo que pretende evitar e dispensa prova do dano efetivo, a precaução pressupõe uma relação causaefeito não unívoca, exige uma intervenção antes da prova científica de um dano incerto cuja ocorrência pretende evitar e dispensa a prova do dano ou da causa ou até do nexo causal. (MARTINS, 2002, p. 24 e ss.)

Esses dois princípios estão presentes no combate à exploração predatória e na pauta da preocupação mundial. O objetivo sete do PNUD - garantia da sustentabilidade ambiental - deixa essa intenção bastante clara em três de suas metas:

1. Integrar os princípios do desenvolvimento sustentável nas políticas e programas nacionais e reverter a perda de recursos ambientais;

2. Reduzir a perda de diversidade biológica e alcançar, até 2010, redução significativa na taxa de perda;

3. Reduzir pela metade, até 2015 , a proporção da população sem acesso permanente e sustentável a água potável segura e esgotamento sanitário.

A aproximação do fim do prazo previsto pelas metas enseja breve levantamento sobre os resultados alcançados. Segundo Relatório dos Objetivos de Desenvolvimento do Milênio 2013, elaborado pela Organização

${ }^{5}$ Disponível em www.onu.org.br/rio20/img/2012/01/rio92.pdf. Acesso em: 16 jun. 2015 vol.09, nº. 01, Rio de Janeiro, 2016.pp. 324-348 
das Nações Unidas (ONU), houve progresso global nas metas correspondentes a integrar os princípios do desenvolvimento sustentável nas políticas e programas e reverter a perda de recursos ambientais, há exemplos de sucesso, como a redução de $98 \%$ do consumo de substâncias que destroem a camada de ozônio. No que diz respeito a pela metade a proporção da população sem acesso permanente e sustentável à água potável e ao esgotamento sanitário, foi atingida cinco anos antes do prazo estipulado. No Brasil, a população urbana em condições de moradia inadequada caiu de 53,3\%, em 1992, para 36,6\% em 2012, um avanço significativo, segundo expressão do próprio relatório nacional de acompanhamento (2014).

As metas importam em proposição para que o homem busque formas de tornar compatível o desenvolvimento econômico e social com o equilíbrio ambiental. Essas metas induzem também que o ganho econômico só pode ser considerado riqueza quando for perene, crescente e cíclico, com proveito para todos. Fora disso há retrocesso, com ilusão de bonança.

No contexto dessas três metas consegue-se inferir que a sustentabilidade envolve necessariamente crescimento econômico, preservação dos recursos ambientais e proveito às populações. $\mathrm{O}$ crescimento é, portanto, conceito correlato à sustentabilidade, o primeiro sem o segundo é quimera; o segundo sem o primeiro, estagnação.

A sustentabilidade se expressa no que a doutrina convencionou chamar de "tridimensionalidade da sustentabilidade" (FOLADORI, 2002, p. 105):

I. Sustentabilidade ecológica;

II. Sustentabilidade econômica;

III. Sustentabilidade social.

Na primeira, há preocupação em assegurar a capacidade de regeneração das espécies comprometidas no processo, ou seja, proporcionar que o saldo resultante da absorção dos componentes ambientais para o desenvolvimento de qualquer atividade seja compatível com a capacidade de regeneração necessária para assegurar a continuidade do ciclo.

Nota-se que no Brasil a questão ambiental assumiu status constitucional somente em 1988, conforme faz lembrar Antônio Herman Benjamin (2008, p.68), na medida em que "forjou uma obrigação genérica, substantiva e negativa, mas implícita, de não degradar o meio-ambiente", "deveres erga omnes", em que se tem como coobrigados, indistintamente, o Poder Público, os indivíduos e a coletividade.

A ideologização do debate em torno de preservação ambiental e crescimento econômico gerou distorção no peso que cada uma das dimensões da sustentabilidade representava para tomada de decisões. Conforme sinaliza Mônica Grossi (2013, p.32), o influxo das preocupações ambientais fez com que a perspectiva do capitalismo verde tivesse espaço nos fóruns econômicos, ele reflete a visão de mundo que subordina o modelo 
de organização social aos limites de exploração dos recursos naturais.

Até o início dos anos 80, conforme lembram Maria Elisabeth Kraemer e João Eduardo Tinoco (2011,p. XI), no império da abundância de recursos naturais, os padrões dominantes de produção e consumo foram estabelecidos sem preocupação de preservá-los, pois eram tidos por ilimitados. A partir daquela década "os gastos com proteça o ambiental começaram a ser vistos pelas empresas lideres na o primordialmente como custos, mas como investimentos no futuro e, paradoxalmente, como vantagem competitiva" (TINOCO, KRAEMER, 2011, p.XI).

A industrialização generalizada contribuiu para que o consumidor deixasse de perceber o meio ambiente natural como origem primária de tudo que abastece o mercado. As frutas não eram mais colhidas em árvores, mas em gôndolas de supermercados. A natureza sofria o risco de ser vista como um sistema apartado da sociedade, com insumos disponíveis ao custo da atividade extrativa. Não se cogitava que a água e o verde pudessem ter preço, foram tomados por muito tempo como inesgotáveis. Rodrigo Silva (2013, p.60) corrobora o pensamento e identifica que agressão da humanidade ao meio ambiente foi intensificada com a Revolução Industrial, e "somente a partir da segunda metade do século XX que se desenvolveu uma consciência com relação à questão ambiental do planeta Terra".

O efeito nefasto do padrão de consumo voltado para o ganho em escala sem preocupação com a capacidade de regeneração da natureza reflete na crescente extinção de espécies e ruína de comunidades autóctones. Os benefícios da riqueza gerada em processo que induz esgotamento dos recursos naturais, ainda que divididos equitativamente na comunidade que os cria, são parciais e finitos. Parciais, porque incapazes de contemplar toda a comunidade de excluídos e prejudicados com a exaustão dos recursos naturais. E finito, porque o modelo de produção linear tem noção precisa de começo e fim do processo, inicia com a matéria-prima e finaliza com a colocação dos seus produtos no mercado, mas não se dá conta de que esses mesmos produtos ficarão inservíveis com o tempo e precisarão receber algum destino, ou ainda que a fonte de matéria-prima é limitada.

Não foi apenas o Estado que despertou para a necessidade de reordenação da forma de exploração da natureza, não se trata de um comando normativo, mas um imperativo natural: a indústria não produz, transforma. Com tal noção, a humanidade inteira é compelida a mudanças fundamentais em seus valores, instituições e modos de vida, como forma de assegurar a continuidade da espécie.

Para promover essas mudanças fundamentais, deve-se promover o engajamento de recursos na formação de capital intelectual apto a agir diante das teias da sustentabilidade e do consumo responsável (POMPEU, 2012, p.134). Baseado em Paolo Grossi (1981, p.59) pode-se dizer que a ideia da apropriação de recursos naturais, de modo ilimitado, é fruto das concepções político-econômicas do liberalismo, mas que a nova 
ordem constitucional brasileira obriga a ser reformulada para subordinar-se ao seu fim social, ou conforme acrescenta José Canotilho (1995, p.18), devem concorrer a evolução dos sistemas político-econômicos, com formas mais solidárias de participação dos cidadãos e das instituições.

O meio ambiente aparece na Constituição brasileira quando ela se reporta à função social da propriedade (art. 50, XXII e XXIII) e na distribuição de competência material e administrativa dos entes federativos (arts. 23 e 24). No Título VII, que trata da Ordem Econômica e Financeira, a preocupação com meio ambiente aparece em dois momentos: no Capítulo I, que trata dos Princípios Gerais da atividade econômica (art. 170), bem como ocupa todo o Capítulo VI, “Do Meio Ambiente” (artigos 225 e seguintes).

Conforme faz ver José Canotilho (2010, p. 11) há direito fundamental a meio ambiente ecologicamente equilibrado ${ }^{6}$ e os desafios ambientais crescentes demandam transformação urgente da atuação do Estado. Apesar de a Constituição brasileira não utilizar a expressão sustentável ou sustentabilidade, o conceito decorre do próprio sistema que induz à necessidade de compatibilidade entre o econômico com a defesa do meio ambiente (art. 170 $\mathrm{CR} / 88$ ), permite destacar a relevância jurídica da proteção ambiental e reconhecer a exigibilidade de sua implementação pela via judicial.

Talvez seja mais rigoroso, no contexto conceptual do direito português, falar de um núcleo essencial de um direito fundamental ao ambiente e à qualidade de vida. Este núcleo essencial pressupõe, desde logo, a procura do nível mais adequado de acção, ou seja, que a execução das medidas de política do ambiente tenha em consideração o nível mais adequado de acção, seja ele de âmbito internacional, nacional, regional, local ou sectorial. (CANOTILHO, 2010, p. 14)

Revela-se que a necessidade de preservação ambiental estabelece padrão valorativo, que alcança também o Direito. Esse esquema axiológico repercute na forma como o Estado deve agir para assegurar a livre iniciativa e o direito à propriedade, de modo a tornar efetivos os princípios da ordem econômica, conforme análise que segue.

\section{O ESTADO ECONÔMICO}

O olhar econômico sobre sustentabilidade importa descobrir e esclarecer os efeitos econômicos da exploração dos elementos naturais. Esses elementos assumem a conotação de insumo, passam a ser considerados "recursos naturais" apropriáveis e úteis para geração de riqueza e acúmulo de capital. Independente dessa condição, não se pode perder de vista que o controle do emprego de capitais e o aproveitamento dos recursos naturais fazem parte da ação orquestrada para a "partilha" dos mercados, como bem destaca Friederich Hayek

\footnotetext{
${ }^{6}$ Ele extrai da Constituição portuguesa a configuração do princípio da sustentabilidade como sendo:

i. Tarefa fundamental;

ii. Princípio fundamental da organização econômica;

iii. Incumbência prioritária do Estado;

iv. Direito fundamental;

v. Dever jusfundamental do Estado e dos cidadãos;

vi. Princípio vector e integrador de políticas públicas.
} 
(1977):

\begin{abstract}
Enquanto essa autoridade controladora "protege" o padrão de vida daqueles que considera especialmente confiados ao seu cuidado, privará muitos, em posição bem pior, da maior e talvez única oportunidade de melhorar a própria condição. Se todas as matérias-primas essenciais fossem controladas dessa forma, não haveria indústria nova ou novo empreendimento a que um povo se pudesse lançar sem a permissão da autoridade, nenhum plano de desenvolvimento ou de melhoramento que esta não pudesse frustrar com o seu veto. (Hayek, 1977, p. 241)
\end{abstract}

Nesse sentido, Garrett Hardin (1968, p. 1245) contribui para evidenciar o custo material que envolve o exercício de cada direito e o risco do esgotamento dos recursos finitos, conforme se constata na "Tragédia dos Comuns". Ela ocorre quando uma comunidade utiliza os mesmos recursos, sem preocupação de sustentabilidade ou eficiência, induzindo o esgotamento das fontes e a falência do modo de vida eleito.

Pode-se deduzir que os recursos naturais, o estilo de vida e a técnica do aproveitamento é determinante para assegurar o crescimento populacional e a qualidade com que isso acontece. Garrett Hardin (1968, p. 1247) deixa evidente que a limitação dos recursos disponíveis sempre será um problema, mas deve-se ponderar a possibilidade de contorná-lo com utilização que contemple a capacidade de renovação desses recursos ou dos processos produtivos.

Nota-se que o limite de crescimento econômico ainda não é conhecido. Os insumos, os processos produtivos e a demanda formam tríade que induzem o progresso, entendido neste contexto como dependência cada vez menor da exaustão de recursos naturais. Para promovê-lo as escolhas individuais têm papel relevante, funcionam como indutoras do processo coletivo.

À luz do reconhecimento da importância da preservação ambiental, os valores que sempre orientaram a hermenêutica constitucional exigem a inclusão do dever transgeracional de assegurar a viabilidade humana para as gerações futuras, sempre que se cogitar justiça social. Não se pode doravante, falar em crescimento econômico sem atrelá-lo à sustentabilidade, conforme orienta José Adércio Sampaio (2003, p. 98) ao estatuir que era possível se "falar no Brasil de um direito fundamental ao meio ambiente ecologicamente equilibrado, assim como se pode referir a uma 'ordem ambiental' que completa e condiciona a 'ordem econômica' e que, por topologia, integra-se na 'ordem social".

Pode-se afirmar, sob o escólio de Enrique Leff (2004, p.52), que a racionalidade perseguida não é monofacetada. Essa racionalidade ambiental não está adstrita a uma estrutura econômica específica, nem tampouco o seu universo de valores é restrito. Ela se constitui pela expressão de "pensamentos, princípios éticos, processos de significação, práticas e ações sociais" diversificadas capazes de orientar a concretização de princípios. Desse embate de ideias, para onde convergem os interesses sociais, emergem os valores como a "intervenção do Estado e da sociedade civil com vistas à sustentabilidade" (LEFF, 2004, p.52).

Despertar para a realidade baseada nesses valores não desestrutura o Direito, o densifica, na medida em vol.09, n. 01, Rio de Janeiro, 2016.pp. 324-348 
que preserva a ordem jurídica - pressuposto do Estado de Direito - e assegura o império da lei, conforme decorre do reconhecimento da precedência de direitos, de processos e legitimados para intervir em conflitos.

Como destaca Lenio Streck (2003, p.293) não há como separar a noção de Estado Democrático de Direito da realização dos direitos fundamentais sociais, para ele, essa certeza repudia as soluções que se restringem ao insondável campo da política e da economia, porquanto capaz de falsear a feição democrática que deve reger os processos que conduzem aos ideais republicanos, conforme ensina Fábio Konder Comparato (2006, p.196). Na análise de Misabel Derzi (2005, p.342), instaurou-se a crise jurídica como decorrência do distanciamento da abstração e axiomatização que cedem lugar a outros paradigmas como a informalidade e descrença na força normativa do Direito que subtraem a legitimidade da regra como instrumento de controle e de regulação.

Exemplo da insuficiência dos instrumentos formais do direito foi trazida a lume com decisão recente da corte holandesa, ocorrida em junho de 2015, proferida na lide proposta em 20 de novembro de 1993 pela Fundação holandesa Urgenda ${ }^{7}$ contra o Reino dos Países Baixos (Urgenda Foundation v. Kingdom of the Netherlands). Como solução o órgão julgador determinou que o Estado holandês promovesse significativa diminuição na emissão de poluentes geradores de alterações climáticas. $\mathrm{O}$ acórdão tem fundamento material na defesa do meio ambiente e sustentabilidade. Da perspectiva teórica, baseia-se no princípio da precaução.

A mesma ordem jurídica, que assegura proteção ao meio ambiente, o converte em veículo para dotar de efetividade a igualdade, liberdade e justiça, valores sociais supremos, conforme estatuído no preâmbulo da Constituição brasileira ${ }^{8}$. Esses valores são descompactados ao longo de todo o corpo da Constituição e se estruturam sob a natureza de direitos fundamentais ao identificarem o conteúdo do patamar civilizatório. A implementação desses direitos requer ação positiva do Estado.

Vale lembrar, conforme Fernando Araújo (2008, p.72) reconhece, o conflito entre interesses particulares e coletivos é fonte da maior parte dos dilemas sociais. A dificuldade reside em regulamentar a forma de acesso e utilização dos recursos que se presumem comuns. Em matéria ambiental, importaria em identificar qual o nível de disponibilidade desses recursos, de que modo devem ficar franqueados, como conceber solução distributiva, sem ceder ao assistencialismo ou ao intervencionismo.

A administração bem-sucedida dos recursos comuns é, pois, aquela que tem conseguido manter distintas as questões de mero acesso (que se constata que serão, por definição, irresolúveis) das questões de partilha dos frutos do recurso, do acesso ao rendimento do recurso, sendo que muitas vezes coexiste o acesso livre com o direito à apropriação privada do rendimento gerado pelos recursos (ARAÚJO, 2008, p. 72).

\footnotetext{
${ }^{7}$ Disponível em http://www.urgenda.nl/en/climate-case/. Acesso em: 10 jul. 2015

${ }^{8}$ Preâmbulo da CR/88 - Nós, representantes do povo brasileiro, reunidos em Assembleia Nacional Constituinte para instituir um Estado Democrático, destinado a assegurar o exercício dos direitos sociais e individuais, a liberdade, a segurança, o bem-estar, o desenvolvimento, a igualdade e a justiça como valores supremos de uma sociedade fraterna, pluralista e sem preconceitos, fundada na harmonia social e comprometida, na ordem interna e internacional, com a solução pacífica das controvérsias, promulgamos, sob a proteção de Deus, a seguinte CONSTITUIÇÃO DA REPÚBLICA FEDERATIVA DO BRASIL.
} 
Conforme se viu, a proteção ao meio ambiente é direito fundamental e a sustentabilidade, sua expressão econômica. Implementar direitos relaciona-se com discricionariedade do poder político e capacidade orçamentária. A importância que se dá ao meio ambiente equilibrado não está apenas atrelada à emulação dos arranjos de poder, conforme explorado por Ferdinand Lassale (1988), porque além da dimensão política, encerra a biológica, fazendo-se peculiar. A necessidade de proteção ao meio ambiente prescinde da compreensão que os homens dispõem sobre a complexidade que the é ínsita. As prescrições constitucionais nesse âmbito contam com alto grau de força criadora e normativa, além de justificar a crescente valoração que se dedica à sustentabilidade nas instâncias de poder, conforme processo descrito por Konrad Hesse (1991, p.4).

Ocorre que a expressão do direito ao meio ambiente protegido exige postura ativa, não apenas do Estado, mas de toda a coletividade ${ }^{9}$. A proteção ao meio ambiente submete-se à coordenação dos interesses plurais no seio do Estado-nação previsto por Bresser Pereira (2006, p. 157). Neste formato de Estado, o desenvolvimento humano se revela com dúplice função, é limite intransponível e, simultaneamente, vetor para o crescimento econômico; o Estado vincula os dois como as faces da mesma moeda, um é o reverso do outro, conforme sintetiza Adam Smith (2003, p. 48) a reconhecer que o desenvolvimento e o bem-estar de uma nação só poderiam advir do crescimento econômico e da divisão do trabalho.

Da parcela de obrigação incumbida ao Estado na proteção do meio ambiente, a eficiência a que ele está obrigado a observar ${ }^{10}$, vincula-o compulsoriamente ao orçamento que dispõe. A forma de captação e aplicação desses recursos é ato político majoritário, para onde devem acorrer todas as forças sociais de modo a produzir uma ação plural e coerente com todas os anseios legítimos. Perseguir esses anseios importa definir metas e prioridades vinculados aos objetivos constitucionais. Mas não é só isso. Há que se extrair em que medida é legítima ou desejada a participação do Estado, revelando a opção econômica de sua expressão: liberal, reguladora e intervencionista.

Observa-se, porém, que a limitação orçamentária e as expectativas ampliativas de direitos subjetivos são entraves para ação articulada capaz de gerar resultados proveitosos. A descontinuidade de políticas públicas e obras inacabadas são exemplos da inaptidão para criar projeto de desenvolvimento plural e ao mesmo tempo coerente e uniforme, que consiga responder as questões econômicas fundamentais que versam sobre o papel do Estado na economia e na apropriação dos meios de produção. A ausência de ideologia de consenso resulta em pretensão utópica do reunir, num só Estado, o que há de melhor dos três modelos e sucumbir diante da meta

\footnotetext{
${ }^{9} \mathrm{CR} / 88$ Art. 225. Todos têm direito ao meio ambiente ecologicamente equilibrado, bem de uso comum do povo e essencial à sadia qualidade de vida, impondo-se ao Poder Público e à coletividade o dever de defendê-lo e preservá-lo para as presentes e futuras gerações.

${ }^{10} \mathrm{CR} / 88$ Art. 37. A administração pública direta e indireta de qualquer dos Poderes da União, dos Estados, do Distrito Federal e dos Municípios obedecerá aos princípios de legalidade, impessoalidade, moralidade, publicidade e eficiência e, também, ao seguinte
} 
inalcançável de suprir todas as carências humanas.

Para evitar o esmaecimento das ações que competem ao Estado, os modelos que ele adota precisam dispor de cenários e recursos favoráveis, nos moldes do que ocorreu quando as teorias de Maynard Keynes (1964) tiveram lugar durante a primeira metade do sec. XX. Houve, na ocasião, acomodação da superestrutura econômica e ideológica que promoveu rearranjo institucional, de modo a tornar o projeto viável. Como bem destacou Marcelo Resico (2013, p. 1) pode-se dizer que "os modelos de capitalismo são dados por combinaçôes de políticas econômicas, um determinado conjunto de instituições e um determinado tecido sociocultural".

Não se quer, com a sugestão de cenários favoráveis, pressupor grau de intervenção estatal mais recomendável, mas demonstrar que existe forma de agir mais adequada aos seus objetivos. Busca-se, como ressalta Bresser Pereira (2006, p. 157), um ponto de equilíbrio que evita o Estado 'grande' em demasia, ou 'pequeno' a ponto de retirar os meios necessários para garantir a legitimidade e capacidade para formular políticas, cobrar impostos e impor a lei:

Para que um Estado democrático seja realmente forte é necessário que sua ordem jurídica seja estável e dotada de legitimidade, ou seja, apoiada na nação. Nas sociedades modernas essa estabilidade e essa legitimidade dependem de uma razoável homogeneidade da sociedade nacional, e de instituições que reflitam o estágio de desenvolvimento e os objetivos dessa sociedade. (PEREIRA, 2006, p.157)

Observa-se que a conjuntura que respalda o proveito de determinada política pública é mutável, o que não pode oscilar são os fundamentos que alicerçam o Estado. Everton Gonçalves (2012, p.108) esclarece que nos momentos de crise devem-se buscar alternativas que viabilizem a reorganização institucional conforme a realidade expressa dentro de contexto social, com as peculiaridades dos seus problemas a exigir soluções imediatas e com conflitos sociais que somente propostas de longo prazo serão capazes de equacionar.

As políticas públicas capazes de realizar os objetivos constitucionais devem ser ampliadas gradativamente e não faltam mecanismos para isso. Nesse sentido, o constituinte de 1988 criou alguns instrumentos que não eram contemplados anteriormente nas constituições de 1934 e 1946, como o mandado de injunção, o mandado de segurança coletivo e a ação direta de inconstitucionalidade por omissão. Além dessas poderosas ferramentas de empoderamento social, persistem a ação popular, o plebiscito e o referendo.

$\mathrm{O}$ surgimento das ferramentas que favorecem o agir coletivamente sinaliza crise resultante do esgotamento do modelo individualista, desprendido das preocupações coletivas, entre elas o meio ambiente, esse modelo não é mais capaz de dar solução aos problemas postos. Ainda atrelado aos cânones normativistas baseado em regras e na hermenêutica clássica, esse novo cenário deve ocupar o lugar da ordem vetusta fazendo emergir as preocupações de natureza transindividual, como o ambiental, que demanda alta complexidade técnica e social, e reclama nova postura.

Essa nova visão consiste na percepção de que a relação existente entre proteção ambiental e atuação 
judicial passa necessariamente pelo reconhecimento de que a incolumidade do patrimônio ambiental é expressão de direito fundamental, constitucionalmente atribuído à generalidade das pessoas.

Para manter-se no desempenho da função de concretizar, não poderiam ser outros os reflexos no Judiciário, senão o de ver-se impelido ao engajamento para alcançar posição medial que evite os extremos da ousadia e do imobilismo. Sobre essa empreitada se debruça o próximo item.

\section{ATUAÇÃO DO JUDICIÁRIO NA PROTEÇÃO AMBIENTAL}

Com o pós-positivismo e o constitucionalismo democrático deram-se condições favoráveis para discussão da justiça no âmago do direito. Instauram-se duas formas de ver a relação entre o Estado e a Constituição e o papel do Judiciário diante dela, conforme sistematiza Lenio Streck (2003, p.269): o subtancialismo e o procedimentalismo.

No substancialismo a Constituição passa a ser instrumento da ação estatal na realização dos objetivos previstos em seu próprio texto, reverte-se em meio e fim do Estado, ou nos dizeres de Luis Fernando Sgarbossa (2008, p.2), importa reconhecer o Poder Judiciário legitimado para corrigir distorções desde que fundamentado na Constituição. Ao Estado "se acopla o conteúdo material das constituições, pela via dos valores substantivos que apontam para uma mudança do status quo da sociedade" (STRECK, 2003, p. 261), realocar as opções estabelecidas pelos Poderes diretamente legitimados pelo voto, para subordiná-las à Constituição.

Os maiores defensores do substancialismo são Ronald Dworkin (2007) e Mario Cappelletti (1988). Para essa corrente, a Constituição funciona como horizonte normativo da ordem social e da política democrática, o Judiciário assume papel relevante na garantia dos direitos e na contenção das maiorias que aniquilam o interesse legítimo das minorias. Assim, atua como guardião dos direitos jurídicos e morais que decorrem da tradição e do arranjo político-social. Nesse modelo, ao "juiz impõe-se a tarefa de reconstrução da ordem jurídica - construída, primeiramente, pelo legislador", conforme lembra Carlos Eduardo Ruzyk (2009, p.250), não há desprendimento da norma regra, mas sim o reconhecimento de que os princípios estariam "vinculados a uma dimensão moral que decorreria de instituições políticas concretamente vigentes".

No substancialismo há uma interpretação construtiva do direito no sentido de promover a realização dos direitos fundamentais sociais e emprestar completude à Constituição que alcançou dimensão "dirigentecompromissária-valorativa-principiológica”, conforme expressão cunhada por Lenio Streck (2003, p.280).

No procedimentalismo a distinção entre política e direito reserva ao Judiciário relevância exclusiva no sistema jurídico, seus expoentes Jürgen Habbermas (1997) e Antoine Garapon (1999). Em Jürgen Habermas (1997), a pretensão dos Tribunais Constitucionais para definir de que modo se dá a concretização dos valores materiais previstos na Constituição importa transposição indevida das suas atribuições. Os críticos do 
substancialismo imputam à teoria o desestímulo que promove no comprometimento social para edificação desses valores, menosprezando mecanismos democráticos, por vezes assimétricas. Para essa corrente, o Tribunal Constitucional deve apenas assegurar processo de criação democrática do Direito.

Em matéria ambiental, conforme leciona José Joaquim Canotilho (1995, p.18), a expressão substancialista reconhece a esse ramo do direito a função de ordenador ou regulador das relações do homem com o seu meio. O direito ambiental infiltra-se em outros domínios, público e privado, horizontaliza-se, e nessa vertente atrai para o Judiciário a possibilidade de interferir nos seus conflitos. Essa interferência não se dá de modo aleatório, existe um fundamento de ordem material que é o reconhecimento de que se trata de um direito fundamental, transindividual de terceira geração. Ele foi concebido no modelo brasileiro onde vige o princípio da inafastabilidade que consiste na vedação à exclusão da apreciação do Poder Judiciário de lesão ou ameaça a direito $\left(\mathrm{CR} / 88\right.$ art. $\left.5^{\circ}, \mathrm{XXXV}\right)$.

Observa-se que essa expressão complexa do direito ambiental não se distancia do entendimento do STF conforme se vê na Medida Cautelar da Ação Direta de Inconstitucionalidade n ${ }^{\text {o }} 3540$ de 03 de fevereiro de 2006. O Ministro Celso Mello como relator trouxe sínteses relevantes:

1. A preservação à integridade do meio ambiente é um direito (art. 225), metaindividual, de terceira geração, que consagra o postulado da solidariedade;

2. A criação de espaços territoriais especialmente protegidos e a intervenção judicial justificam-se pela necessidade de impedir transgressão ao direito ambiental e a irrupção de conflitos intergeracionais (cf. art. $\left.225, \$ 1^{\circ}, \mathrm{III}\right)$;

3. A alteração e supressão do regime jurídico dos espaços territoriais estão sujeitos ao princípio constitucional da reserva de lei.

O reconhecimento da anterioridade legal atrai outra questão para o cerne do problema ambiental. Não se discute mais a natureza do direito ao meio ambiente protegido, sobre o âmbito da competência e funções dos Poderes de Estado, nem a necessidade de tornar o aproveitamento dos recursos ambientais sustentáveis. O problema passa a se identificar à possibilidade de restrição ao direito de propriedade, diante de ameaça de dano ambiental irreversível, em caso de inércia da entidade competente para emissão do ato normativo correspondente (o legislador ou a administração).

Ainda na decisão, há evidente preocupação em traçar paralelo da relação entre economia (art. 3º II, c/co art. 170, VI) e ecologia (art. 225). Consta do acórdão que a solução oferecida ao julgador, quando da colisão de direitos fundamentais, é servir-se de critérios de superação. Essa realidade obriga à acomodação das funções de Estado, elas devem aprender a dialogar com o amplo espectro de direitos sociais assegurados e com a possibilidade de arguição da validade das escolhas de políticas públicas. 
O risco da inação dos Poderes, cujo provimento se dá por eleição - Legislativo e Executivo -, é tanto maior quanto o investimento na perpetuação do poder. O provimento de vagas por concurso e a existência de carreira criam condições aos membros do Judiciário para alinhar as decisões com os valores constitucionais, ainda que impopulares, conforme sugere Luís Roberto Barroso (2012, p.30) quando postula que "juízes não podem ser populistas e, em certos casos, terão de atuar de modo contramajoritário".

A conservação e a promoção dos direitos fundamentais, mesmo contra a vontade das maiorias políticas, são condições de funcionamento do constitucionalismo democrático. $\mathrm{O}$ magistrado é menos infenso à pressão das urnas, sofrida pelos outros dois Poderes. A legitimidade para atuar com alto grau de discricionariedade e a eficácia relativa das decisões judiciais tem como consequência natural o esvaziamento dos espaços disponíveis para discussões e debates no Legislativo e Executivo. Ambos passam a servir-se do processo judicial para eximir-se da responsabilidade que detêm, conforme George M. Lima (2007, p.68) indicou como compromisso inafastável do magistrado implementar os direitos fundamentais. Assim é perfeitamente razoável aceitar que o Judiciário, quando provocado, dê a melhor concretização possível à norma constitucional, quando o legislador nada fizer.

Há que se distinguir controle de constitucionalidade, ativismo judicial e judicialização da política. $\mathrm{O}$ controle de constitucionalidade está previsto na própria Constituição e consiste na necessária intervenção judicial para verificar a adequação e compatibilidade de norma inferior aos mandamentos constitucionais.

Judicialização é gênero da qual judicialização da política e ativismo judicial são espécies (BARROSO, 2012, p.24). No primeiro a política invade o direito na segunda o direito invade a política. Direito e política são componentes inversamente proporcionais no produto dessa interação. $\mathrm{O}$ ativismo importa transposição dos limites hermenêuticos da norma, conforme sugere Lenio Streck (2011, p.15). O juiz abandona as diretrizes ditadas pela norma para regular uma situação não contemplada por ela, ou não prevista daquele modo, atendendo suas conviç̧ões pessoais para a solução do caso concreto. Ativismo decorre da ampliação dos poderes e competências que o órgão julgador se autoconfere. Há invalidação de decisões de outros poderes, atuando como ator político e intérprete moral da sociedade.

Situação diversa é a judicialização da política e a politização da justiça. No primeiro observa-se a migração do espaço público para deliberações e luta por garantia e efetividade de direitos que passam a ocorrer prioritariamente no Judiciário, abrange direitos difusos e coletivos. Essa situação relega a segundo plano outras instâncias como espaços de luta para a conquista de direitos. Conforme expressa Luís Roberto Barroso (2012, p.31), na politização da justiça há subversão para fazer convergir a noção do que é correto e justo à vontade de quem detém o poder.

Verifica-se que a forma de interação do Judiciário com os outros dois poderes está em crise, a separação clássica identificou que o papel e os limites de atuação não são fixados de maneira abstrata, e dissociada da 
realidade cultural e política onde está inserido. A busca de equilíbrio em época de franca expansão de direitos sociais, com esgotamento das instâncias ordinárias é cenário propício para ousadias.

A interpretação baseada em valores morais, dirigida por princípios e um ideário difuso importa na ausência de distinção ontológica entre valor e regra, função social e meio ambiente. No Brasil, o ambiente intelectual e político que se formou após a Constituição de 1988 importou numa consciência progressista da função republicana do Poder Judiciário.

Respaldado nessa consciência, há justificativa para a atuação judicial construtiva, no sentido de prover as manifestações judiciais de formalismo que busque perfeição, maximização dos direitos e capacidade de leitura mais adequada da Constituição. O cenário processual traz também a vantagem do particularismo, análise específica caso a caso, avaliando as consequências da pretensão como projeto para o futuro.

A ideia que os julgadores deveriam ficar restritos ao caso concreto, atrelados, tanto quanto possível, às normas, encontra maior sustentação teórica na argumentação de que se trata de um poder contra-majoritário, onde um número reduzido de julgadores seria capaz de afastar a deliberação de centenas de legisladores, inovando sem preocupar-se com os limites da lei.

Não se desconhece que a judicialização desloca o eixo decisório dos Poderes Legislativo e Executivo para o Judiciário, ainda que o último não tenha atribuição e recursos suficientes para fazer adequações necessárias no orçamento público. O argumento da perda da soberania popular, que decorreria da destituição da representatividade dos que elaboraram as leis, é falacioso.

A representatividade e legitimidade da atuação judicial, nos casos em que a legislação é insuficiente, são capazes de se fazerem democráticas. Essa atuação judicial decorre da inafastabilidade que institui a tutela judiciária como instância inescusável de resolução do conflito. O provimento judicial deve estar preso à obrigação de proporcionar o preenchimento de lacunas com garantia da ordem constitucional, esta sim, escolhida como fundamento vinculante da estruturação do estado republicano e das relações privadas.

A necessidade de fundamentação e vinculação a precedentes consolidados limita casuísmos e inibe pressões espúrias. Não se pode esquecer que a atuação do STF, no papel de Corte Constitucional, acontece em difusa fronteira que separa o político e o jurídico, na medida em que se encontra incumbido do controle híbrido de uma Constituição analítica. Ressalte-se que a realidade brasileira comporta amplo espectro de direitos a serem assegurados, e que estão inseridos em situação econômica incapaz de dar cobro às propostas que se convertem em leis. Lembre-se ainda que essas leis são, por vezes, geradas sem compromisso de manter a coerência sistêmica do ordenamento, ou viabilizar sua execução. 


\section{CONCLUSÃO}

O meio ambiente como tema central nas discussões mundiais permitiu a formação de postura científica que o identifica como valor relevante em toda ordem de deliberação, influindo na estrutura econômica e política, para dali repercutir na superestrutura. Essa importância foi reconhecida no ordenamento nacional, e nessa vertente o meio ambiente foi incluído na Constituição brasileira de 1988. O disposto no art.225 do texto constitucional tornou-se paradigma no âmbito internacional no que é pertinente à proteção do meio ambiente equilibrado.

$\mathrm{Na}$ condição de preocupação angular, a natureza constitui-se garantia de sobrevivência biológica da espécie humana e nesse diapasão cumpre minimizar a visão antropocêntrica, na medida em que revela a incapacidade do homem de subordinar indefinidamente a natureza, compreende-se que ser agente da sustentabilidade implica no dever do homem de aprender a conciliar custodia e gozo da natureza, ou seja preservar e fruir.

Nessa perspectiva erigir a preocupação com sustentabilidade à norma de status constitucional promove mudança na relação entre o homem e a natureza, que até então era de exploração para converter-se em cooperação. Contribui para despertar a consciência ecológica e econômica de que a natureza continua sendo fonte primeira da cadeia produtiva, por mais complexa e desenvolvida tecnologicamente que seja.

Revela-se que a preocupação ambiental auxilia a reconhecer que os fenômenos naturais são apenas um componente dos efeitos deletérios que se lhes imputa. Essas consequências que ameaçam a ocupação humana resultam, sobremaneira, da incapacidade do homem respeitar limites na apropriação dos espaços e recursos naturais, e nesse sentido, estende sua cadeia causal até encontrar-se com a ineficiência de planejamento, inclusive normativo, o que atrai o tema para o âmbito jurídico.

Nota-se que o conceito de sustentabilidade traduz aspectos ambientais, sociais e econômicos, vinculados entre si. No que se refere ao aspecto econômico a interpenetração da ideia de crescimento e desenvolvimento resvala na necessidade de assegurar que o crescimento econômico seja contínuo e perene, ou em outras palavras, gradativo e com ânimo permanente.

Sob a mesma vertente, assegurar que a proteção ambiental seja efetiva importa tomar o Direito como Ciência Social aplicada, admitir que está dentro do seu escopo agir propositivamente, transformar, ser capaz de sinalizar comportamento que induz liberdade, sem descuidar da necessidade de repartir obrigações. Para alcançar essa pretensão, o Direito se dispõe a promover a organização econômica do Estado na tentativa de fazer com que antagonismos entre crescimento econômico e proteção do meio ambiente sejam substituídos pela visão de complementaridade.

Pondera-se que o olhar econômico sobre sustentabilidade revela que a exploração dos elementos vol.09, nº. 01, Rio de Janeiro, 2016.pp. 324-348 
naturais exige equilíbrio adequado entre o dever conjunto que compete à livre iniciativa, ao Estado e à sociedade de preservar o meio ambiente. A concorrência pela apropriação da maior quantidade possível de "recursos naturais" é deficiência para as quais as economias de mercado também estão suscetíveis. A vulnerabilidade do mercado para expurgar, ou inibir, as posturas predatórias antes do seu esgotamento, revela a importância da ação estatal, até mesmo nos sistemas capitalistas.

Vale ressaltar que a atuação do Poder Judiciário é marcante para resolver conflitos entre os princípios da ordem econômica limitados pela moldura deôntica da proteção ambiental, o que impõe hermenêutica que respalde a fundamentação dos valores. Nesse sentido, admitir a intervenção judicial na concretização de direito a meio ambiente saudável não afasta o dogma da divisão funcional do poder.

O reconhecimento de que a Constituição agrega aspectos intervencionistas demanda atuação judicial e redefinição na relação entre os Poderes do Estado. Essa exigência não exclui a participação da sociedade nesse múnus coletivo. O Estado Democrático de Direito, assenta-se na realização dos direitos fundamentais e na possibilidade de estabelecer conexão entre direito, política e economia.

Repete-se que a Constituição brasileira é propositiva, compromissória e assume feição de estatuto jurídico-político. O ativismo - tomado como transposição dos limites hermenêuticos da norma para atender as conviç̧ões pessoais do julgador - não deve ser confundido com o esforço judicial de preenchimento das lacunas do ordenamento, a providência necessária para prevenir o risco ambiental e no estrito âmbito necessário para tornar efetiva a previsão constitucional.

Por esse modo, as três formas de expressão estatal, estão igualmente comprometidas com as diretrizes constitucionais e têm o dever de persegui-las com as prerrogativas das quais dispõem. A tripartição fornece múltiplos canais de captação dos anseios sociais, que vão desde demandas coletivas de vulto até os mais atomizados interesses de expressão individual como o processo judicial. Para suprir essa necessidade, incapaz de ser atendida apenas com a legislação positivada, tornou-se insuficiente a hermenêutica clássica, pois carece da hermenêutica de princípios, essa que faz derivar legitimidade ao Judiciário para agir em favor da efetivação de direitos difusos e transindividuais, em questões inerentes às políticas públicas ambientais.

\section{THE SCOPE OF THE JUDICIARY POWER IN PROTECTING THE ENVIRONMENT WITHIN THE ECONOMIC STATE}

\section{Abstract}

The scope of this article is to analyze the performance of the Judiciary Power before the environmental protection demand, under Article 170, Title VII of the Brazilian Constitution of 1988, which deals with the "Economic and Financial Order." It shows that the dichotomy between economic growth and human development requires the 
Judiciary Brazilian posture able to convert the judicial process instrument and timeliness suitable to the legitimate interference in environmental policy. The incursion in the formation of economic status allows us to identify, among the liberal, regulatory or interventionist postures, the one that best identifies the Brazil in 2015. In this aspect, the protection of the environment is seen as a general duty, fundamental right and value, all capable of balizar performance of government and social agents. Along with economic growth, environmental protection is added to social concerns to build the concept of sustainability. After defining sustainability, the text moves towards indicate the judge's performance limits, investigates the chances of activism. From the nature point of view, research is applied. As for the approach is qualitative, since in consideration of the objectives is exploratory. Regarding the technical procedures is bibliographical, documentary and case law.

Keywords: Judiciary Power. Environmental Protection. Economic Order. Human development. Activism.

\section{REFERENCIAS}

ARAÚJO, Fernando. A tragédia dos baldios e dos anti-baldios: o problema económico do nível óptimo de apropriação. Coimbra: Edições Almedina, 2008.

BARROSO, Luís Roberto. Judicialização, ativismo judicial e legitimidade democrática. (Syn) thesis, 2012. Disponível em: <http://www.e-publicacoes.uerj.br/ojs/index.php/synthesis/ article/ view/7433>. Acesso em: 31 maio 2015.

BECK, Ulrich. La Sociedad del Riesgo. Barcelona: Paidós, 1998.

BENJAMIN, Antônio Herman de Vasconcellos. O meio ambiente na Constituição Federal de 1988. Informativo Jurídico da Biblioteca Ministro Oscar Saraiva, v. 19, n. 1, jan./jun. 2008, p. 37-80, 2008.

BRASIL. Constituição da República Federativa do Brasil: promulgada em 5 de outubro de 1988. Disponível em <http://www.planalto.gov.br/ccivil_03/Constituicao/Constituicao.htm>. Acesso em: 08 de jun. de 2015.

Objetivos de Desenvolvimento do Milênio: Relatório Nacional de Acompanhamento/ Coordenação: Instituto de Pesquisa Econômica Aplicada e Secretaria de Planejamento e Investimentos Estratégicos; supervisão: Grupo Técnico para o acompanhamento dos ODM. - Brasília: Ipea : MP, SPI, 2014.

Supremo Tribunal Federal. Medida Cautelar na Ação Direta de Inconstitucionalidade nº 3540, Tribunal Pleno. Autor: Presidente da República e outros. Demandado: Procurador-Geral da República. Brasília, DF, 03 de Fevereiro de 2006. Disponível em: <http://vlex.com/vid/-41548517>. Acesso em: 8 jun. 2015.

Recurso Extraordinário no 583151, Decisão da Presidência. Ator: Ministério Público Federal. Demandado: Alberto Martins Pires Matos. Relator: Min. Teori Zavascki. Brasília, DF, 10 de abril de 2014. Disponível em: <http://vlex.com/vid/-511779930>. Acesso em: 8 jun. 2015.

Recurso Extraordinário no 673681, Decisão Monocrática. Autor: União. Demandado: Raimundo Rufino de Araujo. Relator: Min. Celso de Mello. Brasília, DF, 05 de dezembro de 2014. Disponível em: <http://vlex.com/vid/549417338>. Acesso em: 8 jun. 2015.

Tribunal Regional Federal (1ª Região). Ação Rescisória no ${ }^{0}$ 2001.01.00.037276-0, Terceira Seção. Autor: Destilaria Alcidia S/A. Demandado: União Federal. Relator: Desembargador Federal Souza Prudente. Brasília, DF, 15 de Fevereiro de 2005. Disponível em: <http://vlex.com/vid/-51939621>. Acesso em: 8 jun. 2015.

CANOTILHO, José Joaquim Gomes. O Princípio da sustentabilidade como Princípio estruturante do Direito Constitucional. Tékhne-Revista de Estudos Politécnicos, 2010. Disponível em: _vol.09, no.01, Rio de Janeiro, 2016.pp. 324-348 345 
<http://www.scielo.mec.pt/scielo.php?pid=S1645-99112010000100002\& script=sci_arttext\&tl ng=en>. Acesso em: 8 jun. 2015.

Protecção do Ambiente e Direito de Propriedade. Coimbra: Coimbra Editora, 1995.

CAPPELLETTI, Mario. Juízes Legisladores? Porto Alegre: Fabris, 1988.

CARVALHO, Carlos Alberto; SOUSA, Marco Túlio. A quarta ferida narcísica: a crise da ciência moderna e suas implicações para as pesquisas em comunicação. Revista Comunicação Midiática, v. 7, n. 3, p. 109-129. Belo Horizonte: 2012.

CIDIN, Renata da Costa Pereira Jannes; SILVA, Ricardo Siloto da. a pegada ecológica em relação ao homem, à natureza e à cidade. Disponível em: <http://www.ecoeco.org.br/backup/ conteudo/publicacoes/encontros/v_en/Mesa3/1.pdf>. Acesso em: 15 out. 2015.

COLOMBO, C.; DIAS, E.; MONTEIRO, G.; COELHO, M. Meio ambiente: seus conceitos e paradigmas. Revista Tessituras Geográficas, v. 1, n. 1, p. 55-65, 2012.

COMPARATO, Fábio Konder. Ética. São Paulo: Companhia das Letras, 2006.

DERZI, Misabel Abreu Machado. Mutações, complexidade, tipo e conceito, sob o signo da segurança e da proteção da confiança. Tratado de direito constitucional tributário: estudos em homenagem a Paulo de Barros Carvalho. São Paulo: Saraiva, 2005.

DWORKIN, Ronald. Levando os direitos a sério. (Taking rights seriously). Tradução de Nelson Boeira. São Paulo: Martins Fontes, 2007

FOLADORI, Guillermo. Avanços e limites da sustentabilidade social. Revista paranaense de desenvolvimento, $\mathrm{n}$. 102, jan/jul, p. 103-113, 2002. Disponível em: <http://dialnet.unirioja.es/ servlet/articulo?codigo=4813391>. Acesso em: 13 jun. 2015.

FREUD, Sigmund. O inconsciente (Edição Standard Brasileira das Obras Psicológicas Completas de Sigmund Freud, Vol. 14). 1996.

GARAPON, Antoine. O juiz e a democracia: o guardião das promessas. Rio de Janeiro: Revan, 1999.

GONÇALVES, Everton das Neves, STELZER, Joana. Eficiência e direito: pecado ou virtude; uma incursão pela análise econômica do direito. Revista Jurídica, 2012. Disponível em: <http://revista. unicuritiba.edu.br/index.php/Revjur/article/view/412>. Acesso em: 19 nov. 2014.

GROSSI, Mônica. Questão ambiental e a construção de outro metabolismo social. Argumentum, v. 5, n. 1, p. 32 45. Vitória: 2013.

GROSSI, Paolo. An alternative to private property: collective property in the juridical consciousness for the nineteenth century. Chicago: The University of Chicago Press, 1981.

HABERMAS, Jürgen. Democracia e Direito entre facticidade e validade. Rio de Janeiro: Tempo Brasileiro, 1997.

HARDIN, Garrett. The tragedy of the commons. Science Magazine, New Series, v. 162, n. 3859, p. 1243-1248, 
dez. 1968

HAYEK, Friedrich August. O caminho da servidão. Instituto Ludwig von Mises, 1977.

HESSE, Konrad. A força normativa da constituição (Die normative Kraft der Verfassung). Tradução de Gilmar Ferreira Mendes. Porto Alegre: Sergio Antônio Fabris Editor, 1991.

KEYNES, John Maynard. Teoria Geral do Emprego, do Juro e do Dinheiro, Fundo de Cultura. Rio de Janeiro: 1964

LASSALE, Ferdinand. A essência da Constituição. 2 ed. Rio de Janeiro: Liber Juris, 1988.

LEFF, Enrique. Aventuras da epistemologia ambiental: da articulação das ciências ao dialogo de saberes/Enrique Leff; tradução de Glória Maria Vargas. Rio de Janeiro: Garamond, 2004.

LIMA, George Marmelstein. Proteção judicial dos direitos fundamentais: diálogo constitucional entre o Brasil ea Alemanha. Niterói: Universidade Federal Fluminense, 2007.

MANTOVANI, Waldir. Relação homem e natureza: raízes do conflito. Revista Gaia Scientia. 2009.

MARTINS, Ana Gouveia e Freitas. O princípio da precaução no Direito do Ambiente. Lisboa: Associação Acadêmica da Faculdade de Direito de Lisboa, 2002.

MEFFE, G.K. \& CARROL, C.R. 1994. What is conservation biology. In: MEFFE, G.K. \& CARROL, C.R. (eds) Principles of conservation biology. Sunderland: Sinauer Associates, Inc., p. 3-23.

MILARÉ, Édis. Princípios fundamentais do direito do ambiente. Revista Justitia, v. 181/184. São Paulo: Revista dos Tribunais, 1998

NUNES, Antônio José Avelãs. Do estado liberal à "revolução keynesiana”. Estudos Jurídicos. Revista da PUC/PR, 1997. Disponível em: <http://www.odiario.info/b2-img/avelasnunes.pdf>. Acesso em: 8 jun. 2015.

ORGANIZAÇÃO DAS NAÇÕES UNIDAS. Declaração do Rio sobre Meio Ambiente e Desenvolvimento. Rio de Janeiro, 1992. Disponível em <www.onu.org.br/rio20/img/2012/01/rio92.pdf >. Acesso em: 16 jun 2015

PNUD Brasil - Programa das Nações Unidas para o Desenvolvimento. Disponível em: $\overline{<h t t p: / / w w w . p n u d . o r g . b r / O D M 7 . a s p x>. ~ A c e s s o ~ e m: ~} 6$ jun. 2015.

PEREIRA, Luiz Carlos Bresser. O Conceito Histórico de Desenvolvimento Econômico. Biblioteca digital, 2006. Disponível em: <http://bibliotecadigital.fgv.br/dspace/handle/ 10438/1973>. Acesso em: 21 mar. 2015.

POMPEU, Gina Vidal Marcílio. A dimensão internacional da crise financeira e seus reflexos no plano das instituições de cooperação supranacional. Gruppodipisa.it, 2012. Disponível em: <http://www.gruppodipisa.it/wp-content/uploads/2012/09/Pompeu.pdf>. Acesso em: 8 jun. 2015.

Crescimento econômico e desenvolvimento humano: entre a soberania do Estado e a proteção internacional dos direitos do homem. Doi: 10.5020/2317-2150.2012. Pensar Revista de Ciências Jurídicas, 2012. Disponível em: <http://ojs.unifor.br/index.php/rpen/article/view/2280>. Acesso em: 8 jun. 2015.

RAWLS, John. Uma Teoria da Justiça. 3ả edição. São Paulo: Martins Fontes, 2008. 
RESICO, Marcelo. O debate sobre os modelos de capitalismo e a economia social de mercado. KonradAdenauer-Stiftung e.V., n. Junho, 2013. Disponível em: <http://www.uca.edu.ar/uca/common/grupo83/files/O_debate_sobre_os_modelos_de_capitalismo_e_a_ ESM.pdf>. Acesso em: 8 jun. 2015.

ROVANI, Anatércia. Ética Ambiental a Problemática Concepção do Homem em Relação à Natureza. Vivências: Revista Eletrônica de Extensão da URI, v. 6, n. 11, p. 41-48, 2011.

RUZYK, Carlos Eduardo Pianovski. LIBERDADE (S) E FUNÇÃO: Contribuição crítica para uma nova fundamentação da dimensão funcional do Direito Civil brasileiro. Curitiba: Universidade Federal do Paraná, 2009 .

SAMPAIO, José Adércio Leite. Constituição e Meio Ambiente na Perspectiva do Direito Constitucional Comparado. Princípios de Direito Ambiental na Dimensão Internacional e Comparada. SAMPAIO, José Adércio Leite; WOLD, Chris; NARDY, Afrânio (orgs.). Belo Horizonte: Del Rey, 2003.

SGARBOSSA, Luís Fernando. Do Estado-Providência ao Mercado-Providência: Direitos sob a "reserva do possível” em tempos de globalização neoliberal. Curitiba: Universidade Federal do Paraná - UFPR, 2009.

SILVA, Rodrigo Zouain da. Os desafios do direito ambiental no limiar do século XXI diante da ineficácia do sistema jurídico ambiental brasileiro. Veredas do Direito, v. 9, n. 18, p. 57-87, 2013.

SMITH, Adam. A riqueza das nações: uma investigação sobre a natureza e as causas da riqueza das nações. São Paulo: Madras, 2009.

STRECK, Lenio Luiz. Contra o neoconstitucionalismo. Constituição, Economia e Desenvolvimento: Revista da Academia Brasileira de Direito Constitucional.V. 4, Jan-Jun, p. 9-27,2011.

Jurisdição constitucional e hermenêutica: perspectivas e possibilidades de concretização dos direitos fundamentais-sociais no Brasil. Novos estudos jurídicos, 2003. Disponível em: <http://www6.univali.br/seer/index.php/nej/article /view/336>. Acesso em: 8 jun. 2015.

TINOCO, João Eduardo Prudêncio; KRAEMER, Maria Elisabeth Pereira. Contabilidade e gestão ambiental. In: Contabilidade e gestão ambiental. $3^{\mathrm{a}}$ ed. Atlas, 20011. VitalBook file.

Urgenda Foundation. Landmark climate change lawsuit. Amsterdam, 2015. Disponível em <http://www.urgenda.nl/en/climate-case/>. Acesso em: 10 jul. 2015.

VASCONCELOS, Arnaldo. A questão das normas constitucionais sem juridicidade. V18 n³ p. 712 . Pensar Revista de Ciências Jurídicas, 7 fev. 2014. Disponível em: <http://ojs.unifor.br/index.php/rpen/article/view/2806>. Acesso em: 21 abr. 2015

Trabalho enviado em 16 de setembro de 2015.

Aceito em 25 de outubro de 2015. 